\title{
Crenças de alunos de um curso técnico sobre o papel da tradução no ensino instrumental de línguas
}

\author{
Patrícia Dias Reis FRISENE \\ UNESP - São José do Rio Preto \\ patdrfrisene@hotmail.com
}

\begin{abstract}
Resumo
O presente artigo visa apresentar os resultados de uma pesquisa-ação envolvendo crenças sobre tradução no ensino instrumental de línguas. Os dados foram coletados por meio de anotações em diários e questionários. O levantamento das crenças dos alunos ajudou a professora na seleção dos materiais e direcionou sua prática pedagógica em sala de aula. Os alunos puderam refletir sobre a complexidade do processo tradutório e os diferentes papéis da tradução na aprendizagem de língua estrangeira.
\end{abstract}

Palavras-chave: crenças de alunos; tradução; Inglês Instrumental.

\begin{abstract}
This paper aims at presenting results of an action-research on students' beliefs about translation in ESP courses. Data were collected through questionnaires and notes on diaries. The author has used students' beliefs as a guidance to select materials for the course, as well as for shaping her teaching approach. Participants discussed the complexity of the translation process and the different roles played by translation in second language learning.
\end{abstract}

Keywords: students' beliefs; translation; ESP.

\section{Introdução}

Considerando a natureza situacional dos programas e das práticas pedagógicas, muitas pesquisas em Linguística Aplicada têm discutido a importância da formação crítica de professores de línguas para ampliar e melhorar as oportunidades de aprendizagem em sala de aula (HAWKINS; NORTON, 2009). Nessa perspectiva, observamos a 
necessidade de estudos que contribuam para a formação de professores de língua estrangeira (LE) que atuam em cursos técnicos, assim como a exploração de crenças e pressupostos teóricos sobre o papel da tradução nesse contexto.

Esta pesquisa iniciou-se com a leitura dos conteúdos programáticos da disciplina de Inglês Instrumental de diferentes cursos oferecidos em uma Escola Técnica Estadual (ETEC) do interior paulista. Em seguida, constatamos que todos os programas indicavam a tradução de textos especializados como uma das habilidades a serem desenvolvidas durante o curso, contudo não explicitavam quais aspectos da tradução deveriam ser enfatizados no referido contexto. Em um dos programas, chegamos a encontrar "fundamentos de tradução técnica" como uma de suas bases tecnológicas, sem qualquer informação adicional que orientasse o professor com relação à abordagem didática em sala de aula.

O objetivo do trabalho foi observar as crenças (BARCELOS; VIEIRA-ABRAHÃO, 2006) dos alunos em relação à tradução de textos da área da Informática. A partir de uma avaliação inicial, demos continuidade ao curso e aplicamos uma série de atividades de tradução com o intuito de refletir sobre as contribuições dessa prática no ensino de Inglês Instrumental. Por fim, aplicamos outro questionário para observar se ocorreram mudanças na visão dos alunos sobre a tradução de textos especializados.

O presente estudo buscou responder às seguintes perguntas de pesquisa:

1. Quais crenças sobre a tradução de textos especializados são compartilhadas pelos alunos?

2. A abordagem implementada pela professora/pesquisadora em sala de aula possibilitou a exploração de diferentes aspectos da tradução de textos especializados?

3. A abordagem empregada pela professora/pesquisadora contribuiu para mudanças na visão de tradução dos alunos ao término do curso?

A seguir, apresentaremos a metodologia da pesquisa, sua fundamentação teórica, as análises e discussão dos dados, e nossas considerações finais. 


\section{Metodologia da pesquisa}

Esta investigação foi desenvolvida em uma ETEC, localizada no interior do Estado de São Paulo, com alunos do curso técnico de Informática para Internet do $2^{\circ}$. Módulo (noturno), durante as aulas da disciplina de Inglês Instrumental. A pesquisa foi desenvolvida durante o período de três meses, totalizando 25 horas de aula, ministradas predominantemente em Língua Portuguesa, visto que, conforme o programa da disciplina, o objetivo principal do curso seria desenvolver a habilidade de leitura e interpretação de textos técnicos da área da Informática.

A professora/pesquisadora iniciou o curso utilizando um livro didático que foi, inicialmente, suplementado por materiais produzidos por ela, até ser totalmente substituído. Esse material foi digitalizado e enviado semanalmente por $e$-mail aos alunos. A turma era composta por 39 alunos, em sua maioria, advindos de escolas públicas. Em sala de aula, os alunos podiam usar um computador com acesso à internet, embora o número fosse insuficiente para acomodar um aluno por computador. Por esse motivo, alguns alunos trabalharam em pares. A sala de aula era ampla e dispunha de ar-condicionado e lousa branca. Em face dessas informações, consideramos que o curso discorreu em um local agradável e propício à aprendizagem.

Os dados foram coletados por meio de observação participante, em que o pesquisador "observa-se e observa o outro, torna-se membro do contexto pesquisado, participando de sua cultura e atividades" (VIEIRA-ABRAHÃO, 2006, p. 225). Além disso, também foram coletadas informações por meio de anotações em diários, questionários e de uma avaliação final sobre o curso feita por todos os alunos.

Elaboramos um questionário especificamente com o propósito de observar as crenças dos alunos em relação à prática de tradução de textos especializados. O questionário foi aplicado no terceiro mês de aula e apresentava cinco perguntas. Após responderem ao questionário, foram propostas várias atividades de tradução envolvendo diferentes gêneros textuais da área da Informática.

Partindo da ideia de que a tradução pode envolver dois códigos linguísticos (tradução interlingual), dois sistemas de signos (tradução intersemiótica) e pode ocorrer, até mesmo, dentro de um mesmo código linguístico (tradução intralingual) (JAKOBSON, 1970, p. 64- 
5), a professora/pesquisadora selecionou uma série de textos especializados com o intuito de explorar, além dos aspectos linguísticos, as mensagens que são veiculadas explicitamente ou implicitamente por meio dos diferentes sistemas de signos, verbais ou não-verbais.

As atividades de tradução eram precedidas por exercícios de análise dos elementos macro e microlinguísticos do texto (PAGANO; MAGALHÃES; ALVES, 2009), interpretação e descrição de imagens, leitura instrumental, e encerravam com a elaboração de glossários explicativos em língua materna. Após cada atividade, a professora/pesquisadora realizava uma discussão sobre a experiência dos alunos e suas dificuldades, anotando as informações em seu diário de classe. Também procuramos utilizar o diálogo colaborativo (HAWKINS; NORTON, 2009, p. 36) para construir e mediar significados e visões sobre tradução entre os alunos e a professora/pesquisadora. A seleção das respostas do questionário de crenças e dos comentários registrados no diário de classe da professora/pesquisadora para a categorização dos dados baseou-se não apenas em critérios de frequência, mas também na pertinência dos comentários para a presente investigação.

\section{Fundamentação teórica}

O papel da tradução no ensino de línguas tem passado por constantes reformulações nos últimos anos. A abordagem da Gramática e da Tradução (GT), também conhecida como Metodologia Tradicional, surgiu na época do Renascimento e constitui a abordagem mais conhecida e praticada na história do ensino de línguas. Mais adiante, no século XIX, quando o Método GT perdeu seu espaço para os chamados Métodos Naturais e Método Direto, que enfatizavam a língua oral, a tradução foi praticamente excluída do contexto de ensino de línguas (MALMKJAER,1998).

A Abordagem Comunicativa (AC), segundo Almeida Filho (1998, p. 36), originou métodos que tinham em comum "o foco no sentido, no significado e na interação propositada entre sujeitos na língua estrangeira". Muitos adeptos da AC acreditavam que o professor deveria "evitar" a tradução em sala de aula, alegando 
motivos como (MALMKJAER, 1998, p. 6): "a tradução é radicalmente diferente das quatro habilidades"; "a tradução não é natural"; "a tradução evita que os alunos pensem na LE"; "a tradução produz interferências lingüísticas", entre outros.

Essa visão de tradução no ensino de línguas sofre alterações com o surgimento de práticas e abordagens como a Abordagem Crítica e a Abordagem Sócio-cultural, que celebram a diversidade cultural e a experiência do indivíduo, e buscam promover a reflexão crítica sobre "as formas como as relações de poder são construídas e funcionam na sociedade e até que ponto as práticas políticas, sociais e históricas estruturam a desigualdade educacional" (HAWKINS; NORTON, 2009, p. 33). ${ }^{1}$

De acordo com Cochran-Smith e Lytle (1993 apud ZEICHNER, 2008, p. 539), o movimento da prática reflexiva envolve:

o reconhecimento de que os professores devem exercer, juntamente com outras pessoas, um papel ativo na formulação dos propósitos e finalidades de seu trabalho e de que devem assumir funções de liderança nas reformas escolares. A "reflexão" também significa que a produção de conhecimentos novos sobre ensino não é papel exclusivo das universidades e o reconhecimento de que os professores também têm teorias que podem contribuir para o desenvolvimento e para um conhecimento de base comum sobre boas práticas de ensino. (COCHRAN-SMITH; LYTLE, 1993, apud ZEICHNER, 2008, p. 539)

Nesse ponto de vista, o professor começa a assumir o papel de produtor de conhecimento e sua prática educacional passa a ser definida pelo contexto, o que nos impede de pensar em um único "modelo" ou "método" a ser seguido pelos professores. Essa ausência de modelos prescritivos encoraja o professor de línguas, nesse caso, de Inglês Instrumental, a refletir sobre as possibilidades e limitações de cada contexto e procurar, de forma criativa, materiais e práticas mais adequadas.

\footnotetext{
1 Tradução nossa para: [...] the ways in which power relations are constructed and function in society, and the extent to which historical, social, and political practices structure educational inequity.
} 
Dessa maneira, a fundamentação teórica de nosso trabalho será apresentada abordando três tópicos principais: (1) crenças sobre o ensino e aprendizagem de línguas; (2) ensino instrumental de línguas e abordagem crítica; e (3) tradução de textos especializados e gêneros textuais.

\subsection{Crenças sobre ensino e aprendizagem de línguas}

Investigações envolvendo o conceito de crenças em Linguística Aplicada ocorrem há quase duas décadas no Brasil e no mundo. Surgiram nesse período vários termos para se referirem a crenças baseados em diferentes aportes teóricos. Em geral, teóricos utilizam esse conceito para caracterizar o que os professores sabem, pensam e acreditam sobre o processo de ensinar línguas, embora nem sempre achem que seja possível fazer a distinção entre essas três habilidades.

De acordo com André (1999, apud BARCELOS, 2004, p. 14), as crenças podem ser definidas como "posicionamentos e comportamentos embasados em reflexões, avaliações e em julgamentos que servem como base para ações subsequentes". Na definição de Johnson (1999, apud BARCELOS, 2004, p. 14), as crenças podem ser vistas como um "componente cognitivo, afetivo, e comportamental que influencia o que sabemos, sentimos e fazemos".

Como relata Barcelos (2006, p. 18), algumas visões recentes a respeito de crenças indicam "uma perspectiva mais situada e contextual desse conceito, não mais de uma natureza estática e fixa, como se entendia anteriormente". Por isso, a autora afirma que as crenças exercem grande influência nas ações dos professores e dos alunos, da mesma forma que as ações também podem influenciar as crenças. Contudo, além de identificarmos as crenças, precisamos observar a relação que elas estabelecem com o contexto e com o processo de reflexão dos professores.

Ao apontar uma dissonância entre crenças e ações, Woods (1996) relata que as crenças, pressupostos e conhecimentos (Beliefs, Assumptions and Knowledge, BAK) e o comportamento nem sempre são correspondentes. Segundo o autor, isso acontece porque "o indivíduo pode não estar ciente de um dado comportamento que foi internalizado previamente e que reflete as características de um estado 
anterior na evolução do BAK do professor" (WOODS, 1996, p. 252, apud BARCELOS; VIEIRA-ABRAHÃO, 2006, p.28). Nessa perspectiva, percebemos que a relação entre crenças e ações não pode ser considerada linear ou unidirecional.

Assumindo a complexidade da relação entre crenças e ações, Borg (2006, p. 275-288) afirma que a mudança de comportamento não implica mudança cognitiva, da mesma forma que a mudança cognitiva também não garante mudanças no comportamento. Para o autor, a prática pedagógica dos professores é um processo que se define por interações dinâmicas entre cognição, contexto e experiência. Contudo, Borg acredita que o conhecimento dos professores pode ser aprofundado por meio de cursos e treinamentos e que esse conhecimento pode alterar suas ações, favorecendo, assim, a aprendizagem dos alunos. Partindo desse ponto de vista, esclarece que os estudos sobre cognição podem ser "mais realistas e produtivos" se trabalharem de forma colaborativa com pesquisas na área de ensinoaprendizagem de línguas, uma vez que poderiam adotar perspectivas alternativas de pesquisa.

\subsection{Ensino Instrumental de Línguas e a abordagem crítica}

Por volta de 1977, o Inglês Instrumental é implantado no Brasil pelos departamentos de Letras Germânicas e de Línguas Modernas dos cursos de graduação, pós-graduação e também em algumas escolas técnicas federais. Ao privilegiar o aspecto pragmático da língua, a abordagem instrumental enfatiza o caráter utilitário da língua e a preparação dos alunos para o mercado de trabalho.

$\mathrm{O}$ que no Brasil se convencionou a chamar de Inglês Instrumental corresponde em inglês aos termos Inglês para Fins Específicos (English for Specific Purposes, ESP) e Inglês para Fins Acadêmicos (English for Academic Purposes, EAP). Robinson (1980) define o ESP da seguinte maneira:

Um curso de ESP é intencional e direcionado à realização bem-sucedida de funções educacionais e profissionais. É baseado na análise rigorosa das necessidades dos alunos e deve ser "feito sob medida". (...) Tem uma duração específica. Os alunos são geralmente adultos e podem 
apresentar diferentes níveis de competência. (ROBINSON, 1980$, p. 13$)^{2}$

Apesar de ser um curso que deve moldar-se às necessidades dos alunos, percebemos que ainda há a predominância da utilização de estratégias de leitura nos cursos de Inglês Instrumental (HOLMES; CELANI, 2006) no Brasil. Ao analisar os programas dos cursos de Inglês Instrumental oferecidos pela ETEC, observamos que as estratégias de leitura mais comuns são fazer previsões do conteúdo do texto a partir da análise de títulos, gráficos e ilustrações (non-linear information), concentrar a atenção nas palavras cognatas (cognates) e deduzir o significado de palavras desconhecidas pelo contexto (contextual reference), procurar informações específicas (scanning) ou fazer uma leitura rápida (skimming) para verificar a ideia central do texto (main idea) e usar do conhecimento de mundo e do conhecimento prévio (previous knowledge) do assunto pelo leitor, entre outras. Considerando que a linguagem é objeto e instrumento (VYGOTSKY, 2000) da ação do educador e que é por meio dela que ocorre o processo reflexivo, as atividades de leitura - e de tradução precisam suscitar questões que ultrapassem uma análise estrutural do texto.

Iniciada na Escola de Frankfurt (1976), a Teoria Crítica desafia construtos de racionalidade e de neutralidade ao considerar que "nossos conhecimentos do mundo são construídos por fatores contextuais que são ideologicamente informados" (HAWKINS; NORTON, 2009, p. 31). ${ }^{3}$ Dessa maneira, nossas ideias, linguagens, textos e práticas pedagógicas são construídas nas relações sociais que, inevitavelmente, produzem relações desiguais de poder.

Ao enfocar as desigualdades, o professor de línguas crítico encoraja alunos-professores a refletirem criticamente sobre suas próprias identidades e posicionamentos na sociedade. Tomando por base a relação de imbricação entre indivíduo e sociedade, a reflexão

\footnotetext{
2 Tradução nossa para: An ESP course is purposeful and is aimed at the successful performance of occupational or educational roles. It is based on a rigorous analysis of students' needs and should be 'tailor-made'. (...) It is likely to be of limited duration. Students are more often adults and may be at any level of competence.

3 Tradução nossa para: [...-] our understandings of the world are constructed by contextual factors that are ideologically informed.
} 
crítica preconiza a transformação da ação e focaliza questões éticas e morais. Essa transformação, segundo Liberali (2008, p. 40) envolveria "não só o pensar sobre a prática, mas o desenvolvimento de alternativas de atividade docente em uma perspectiva que veria o papel da escola como local não neutro" e os estudantes como "agentes críticos".

\subsection{Tradução e gêneros textuais}

Os textos pertencentes às áreas de especialidade podem receber diferentes terminologias: "texto especializado" (BERMAN, 1971); "texto técnico" (NEWMARK, 1981); ou "texto pragmático" (AUBERT, 1998), segundo relata Camargo (2007, p. 46). Contudo a distinção entre o que seria um texto especializado e um texto nãoespecializado continua sendo alvo de debates e é o foco de muitas pesquisas na área de Linguística Aplicada.

Sobre as características do texto técnico, científico e especializado, Barros (2004) explica que:

o conjunto não finito dos discursos orais e escritos produzidos por uma área do saber ou do fazer humano constitui um universo de discurso, marcado por uma norma discursiva própria, ou seja, por características comuns e constantes em diversos níveis: léxico-semântico, semânticosintáxico, narrativo e discursivo. [...] A principal característica desse tipo de texto encontra-se, no entanto, em nível lexical, uma vez que veicula unidades lexicais com conteúdos específicos do domínio em questão (BARROS, 2004, p. 44).

Nessa visão, o usuário de uma linguagem de especialidade deve conhecer os padrões próprios de cada universo ou área técnica para ser capaz de compreender e produzir um texto especializado, daí a necessidade de se trabalhar a terminologia técnica de cada área em sala de aula.

Segundo Camargo (2007), a tradução especializada pode abranger várias tipologias textuais distintas como textos científicos das áreas das Ciências Exatas, Biológicas e Humanas; textos técnicotecnológicos, jurídicos, corporativos, jornalísticos, promocionais 
(publicidade, anúncios) etc. As investigações de Camargo sobre a relação entre tipologia tradutória e tipologia textual assinalam que tipos de texto diferentes demandam posturas tradutórias diferentes da parte dos tradutores.

Para Aranha (2004), os gêneros textuais são construídos sóciohistoricamente e por isso não apresentam características prédeterminadas. São eventos codificados inseridos em processos sociais comunicativos, compartilhados pelas comunidades em que ocorrem e reconhecidos por seus membros como legítimos (SWALES, 1990, 1992, apud ARANHA, 2004, p.23). Assim, o usuário de uma linguagem de especialidade deve reconhecer os padrões próprios de cada universo linguístico com base no contexto de partida e de chegada dos textos.

Ambas as conceituações sobre tipologia textual suscitam posturas tradutórias específicas para os textos especializados, porém abrangem critérios diferentes. Pagano (2009) comenta que, dentre as estratégias utilizadas pelo tradutor experiente, encontramos a análise dos elementos macro e microlinguísticos do texto. Por elementos macrolinguísticos entendemos "os aspectos que relevam o funcionamento do texto como um todo, ou seja, o tipo de texto, a função que esse texto geralmente tem, a audiência para a qual está dirigido" (PAGANO, 2009, p. 20-22). Em contrapartida, os elementos microlinguísticos são definidos como "componentes de cada uma das sentenças do texto, que se articulam para se inter-relacionar entre si e dar tessitura ao texto" (PAGANO, 2009, p. 20-22). Segundo a autora, a sensibilidade para lidar com aspectos macro e microlinguísticos de um texto é uma característica do tradutor experiente que, antes de mais nada, também é um leitor proficiente e analista de textos.

Considerando que a tradução, além de ser uma prática linguística, é um evento comunicativo complexo, influenciado pelas orientações sociais, culturais e políticas do contexto em que é realizada, ressaltamos a necessidade de pesquisas que busquem refletir sobre o papel da tradução no ensino de línguas.

A seguir, discutiremos as análises dos dados obtidos em sala de aula junto aos alunos do $2^{\circ}$ módulo do curso técnico de Informática para Internet. 


\section{Análise e discussão}

A análise dos dados foi realizada seguindo as perguntas de pesquisa apresentadas na introdução. Iniciamos o levantamento das crenças dos alunos acerca da tradução especializada com base nas perguntas do questionário de avaliação inicial. Ao longo do curso, registramos alguns comentários e dificuldades relatados pelos alunos durante as atividades de tradução, registrados em diários de classe da professora/pesquisadora. Para encerrar, examinamos se as opiniões dos alunos sobre a tradução de textos especializados apresentam alterações no questionário entregue ao final do curso.

\subsection{Crenças dos alunos em relação à tradução especializada}

Para responder à primeira pergunta de pesquisa que aborda as crenças dos alunos sobre tradução especializada na área da Informática, selecionamos algumas respostas fornecidas pelos alunos no primeiro questionário.

$\mathrm{Na}$ primeira questão os alunos deveriam definir o conceito de texto especializado e suas respostas foram muito variadas, como mostram os excertos a seguir:

[1] "Um texto técnico é um tipo de texto específico sobre determinado assunto, utilizando palavras e linguagem própria daquele tema" ( $D$ - questionário).

[2] O texto técnico é direcionado para explicar ou orientar o leitor de como realizar um procedimento ou aprender um novo procedimento em linguagem padronizada. ( $E$ - questionário)

[3] "Textos voltados para a área da Informática" ( $C$ - questionário)

[4] "É um texto especializado em uma certa área técnica" ( $G$ questionário)

No primeiro excerto, encontramos uma definição muito ampla e vaga sobre o que é um texto técnico, uma vez que todo texto trata de um assunto específico. No segundo excerto, o aluno apóia-se em uma visão de texto como instrumento para aquisição de informações que possibilitem a execução de determinado procedimento técnico. O texto técnico é caracterizado como se fosse um texto pertencente apenas à área da Informática para Internet no excerto 3 , excluindo as demais 
áreas de especialidade. O quarto e último excerto apresenta a única definição mais adequada para o texto técnico.

Com base nas respostas dos alunos, percebemos que muitos deles $(86 \%)$ não apresentavam uma noção clara sobre o que seria um texto técnico ou especializado, suscitando uma discussão sobre suas características e diferentes funções no cenário mundial.

Para trabalhar essa questão, por exemplo, elaboramos uma aula que apresentava um parágrafo retirado de um manual de engenharia computacional e outro parágrafo de um conto retirado de um livro didático. Iniciamos com uma prática de leitura instrumental dos textos e com a elaboração de um glossário que foi realizado em conjunto com os alunos, à medida que identificávamos termos considerados específicos da área da Informática. Para encerrar, os alunos fizeram a tradução dos parágrafos com auxílio da ferramenta "Google tradutor" e comparavam ambos os textos, identificando semelhanças e diferenças entre eles. Nessa aula, discutimos questões referentes às diferenças linguísticas e de produção de cada texto, além de refletir sobre os interesses de cada público receptor. Nesse primeiro exercício de tradução percebemos que os alunos ainda não tinham consciência de que a ferramenta eletrônica utilizada apresenta lacunas que precisam ser preenchidas pelo tradutor "humano". Essa constatação foi importante para suscitar uma reflexão sobre texto e linguagem técnica.

A segunda questão, no questionário de crenças, trata do tipo de informação encontrada em um texto técnico da área da Informática, o que complementaria a primeira questão. Para responder essa pergunta, a maioria dos alunos fala sobre conteúdos técnicos da área:

[5] "Informações específicas, voltadas estritamente para a área a qual foi destinada." ( $R$ - questionário)

[6] "Assunto sobre a internet, computador, etc." (L-questionário)

[7] "Sobre sistemas operacionais, números binários, hardwares, softwares e internet, entre outros.

[8] "Podemos encontrar termos técnicos, a estrutura da língua e de textos, como por exemplo, a estrutura de um e-mail em inglês. ( $T-$ questionário)

Acreditamos que os alunos tenham destacado conteúdos da área em suas respostas, principalmente, por causa do termo 
"informação", que aparece na pergunta. Esse fato suscitou um questionamento por parte da professora/pesquisadora sobre a elaboração do questionário, sugerindo que a pergunta deveria ser reelaborada. Todavia, um aluno [8] observa questões ligadas à tipologia textual e à terminologia técnica, demonstrando maior entendimento sobre o gênero.

Apesar de incompletas, as respostas apresentadas pelos alunos serviram para nortear a professora/pesquisadora com relação às expectativas dos alunos sobre o conteúdo dos textos a serem trabalhados em sala de aula. Considerando as respostas dos alunos, o conteúdo programático da disciplina de Inglês Instrumental e de outras disciplinas específicas do curso, a professora selecionou o material restante.

Voltando à análise do questionário respondido pelos alunos, a pergunta 3 indaga sobre o que acontece durante uma tradução especializada. Observamos que muitas opiniões (79\%) revelam uma visão de tradução como uma simples "transferência" de significados de uma língua para outra, como mostram os excertos seguintes:

[9]: "Verificamos a tradução de cada palavra" (C-questionário) [10]: "Transferimos ele (o texto) de uma linguagem não muito comum para outra que utilizamos, para simplificar e entender melhor o que estamos fazendo. (W-questionário)

Nos excertos 9 e 10 percebemos que os alunos compartilham uma visão redutora de tradução, como um processo simples de busca de termos equivalentes entre as línguas. Para explorar essa questão, elaboramos duas aulas diferentes. Em uma aula, selecionamos um manual de instalação de impressora utilizando um sistema operacional específico. Esse manual apresentava mais da metade das informações na forma de imagens e não deixava dúvidas com relação ao sistema operacional "indicado" para a instalação. A professora/pesquisadora pediu que os alunos explicassem as imagens e esclareceu que essa atividade envolvia a chamada "tradução intersemiótica". Alguns alunos questionaram a necessidade da tradução da imagem por afirmarem que as informações estavam claras para o leitor. Contudo muitos alunos demonstraram dificuldade em explicitar essas informações "supostamente" claras, o que sugeriu uma deficiência na 
construção de textos em língua materna. Esse material também permitiu que explorássemos questões que envolvessem o contexto de produção do material e as relações de poder que ele representa.

Outras associações e papéis da tradução aparecem na opinião dos alunos, conforme mostram os excertos:

[11]: "Buscamos as palavras cognatas, conhecidas e buscamos identificar o sentido geral do texto" ( $G$ - questionário)

[12]: "Além de obtermos a tradução desejada, adquirimos conhecimento sobre o assunto" ( $R$ - questionário)

No excerto 11, o aluno associa a tradução a técnicas de leitura instrumental como a identificação dos termos cognatos e a técnica de skimming. Essa associação pode ter ocorrido pelo fato de a professora ter trabalhado esse assunto nas primeiras aulas do curso. No segundo excerto, o aluno observa a função interdisciplinar da tradução, que pode ser usada para ampliar o conhecimento dos alunos sobre assuntos relacionados à área de especialidade.

Para trabalhar a questão da interdisciplinaridade por meio da tradução, selecionamos textos que abordavam conteúdos de conhecimento específico da área, como a história dos computadores e da internet. Percebemos que os alunos surpreenderam-se ao encontrar informações que já haviam estudado em outras disciplinas e realizaram as atividades mais motivados e confiantes. A tradução desses textos suscitou alguns debates terminológicos, envolvendo, por exemplo, nomes de computadores (ENIAC, Z3, etc.) e termos ligados à internet (site/sítio; chat/ bate-papo; broadband/banda-larga, etc.). Nesse momento, entendemos que a tradução também pode ter desempenhado um papel de ampliação do léxico da língua materna.

Ao analisarmos a pergunta 4 do questionário, que investiga a opinião dos alunos sobre a importância das atividades de tradução em sala de aula, observamos que as respostas foram unânimes:

[13]: "Sim. Ainda mais na área em que estamos, de informática, o inglês é fundamental." (G-questionário)

[14]: "Sim, nos ajuda a compreender mais a língua inglesa." (Cquestionário)

[15]: "Sim, porque dessa forma treinamos nosso inglês e criamos um vocabulário técnico." ( $M$ - questionário) 
[16]: “Sim, pois ajuda-nos a adquirir mais informações.” (J questionário)

Ficou claro para a professora/pesquisadora que todos os alunos consideram importante o conhecimento da língua inglesa na área da Informática, porém alguns alunos não conseguiram justificar de forma clara qual seria a contribuição da tradução dentro do curso. No excerto 14, por exemplo, o aluno enxerga a tradução como uma ferramenta que irá ajudá-lo a compreender melhor a língua inglesa, mas não explica de que forma isso pode acontecer. A tradução é vista como uma ferramenta para a identificação de vocabulário técnico no excerto 15, e na maioria das respostas dos alunos (87\%). Por fim, no excerto 16 encontramos a tradução com a função de informar o aluno sobre determinado assunto referente à área de especialidade em questão.

Como podemos observar, a análise das respostas dos alunos no primeiro questionário mostrou que os alunos necessitam de mais informações sobre outras funções que a tradução pode desempenhar em sala de aula. Diante dessa constatação, a professora/pesquisadora procurou selecionar textos e atividades que pudessem suscitar uma reflexão mais ampla sobre as questões que envolvem a tradução de textos especializados e o ensino instrumental de línguas.

As dificuldades relatadas pelos alunos durante as práticas de tradução de textos especializados em sala de aula refletem desde problemas ligados ao nível de conhecimento da LE até dificuldades em produção de texto em língua materna, e podem ser decorrentes do pouco contato que a maioria dos alunos teve com a língua inglesa.

Após as análises das crenças e das principais dificuldades dos alunos registradas pela professora/pesquisadora, percebemos que os instrumentos de pesquisa utilizados atuaram de forma colaborativa para a escolha dos conteúdos de ensino e a serem trabalhados com alunos do curso de Informática para Internet e orientaram as práticas pedagógicas da professora/pesquisadora, a qual explorou diferentes aspectos da tradução especializada em sala de aula, respondendo, a nosso ver, à segunda pergunta de pesquisa proposta para este trabalho.

A seguir, discutimos os comentários dos alunos ao final do curso, registrados no questionário final. 


\subsection{Comentários dos alunos no questionário ao final do curso}

O questionário entregue ao final do curso teve como objetivo responder à terceira pergunta de pesquisa, ou seja, verificar se a abordagem implementada pela professora/pesquisadora contribuiu para mudanças na visão de tradução dos alunos ao término do curso. Para isso, repetimos a pergunta feita no primeiro questionário sobre o que fazemos quando traduzimos um texto especializado. Do total de 12 alunos que responderam a esse questionário, 9 (nove) identificam diferentes aspectos da atividade tradutória, como nos excertos apresentados a seguir:

[17]: "Aumentamos nosso conhecimento na área de informática; observamos qual a origem de determinado trecho em inglês (se é um manual técnico, um jornal, uma instalação de um aplicativo); vemos o sentido de uso dos termos; observamos o que o autor quis expressar; gravamos e aumentamos o nosso vocabulário em inglês." (A-questionário final)

[18]: "Buscamos o sentido das palavras e, além de praticar nosso inglês, aprendemos que o texto especializado ensina." (M questionário final)

De acordo com os extratos acima, por meio da tradução, identificamos o gênero no qual se insere o texto e buscarmos o(s) sentido(s) do texto ("sentido de uso dos termos"), além das chamadas "intenções" do autor. Além disso, a tradução é apontada como responsável pelo aumento do vocabulário da língua inglesa e pelo aprendizado de novos conteúdos da área da Informática. Essas respostas demonstram um alargamento da visão inicial de tradução como um processo de "busca de equivalentes", expressa no questionário inicial.

Além da visão de tradução como um instrumento de ampliação de conhecimento da língua inglesa e dos conteúdos da área da Informática, algumas respostas dos alunos também revelaram uma preocupação com o contexto de produção e de recepção dos textos:

[19]: "Buscamos compreender de acordo com o universo em que ele (o texto) foi escrito, traduzir para uma linguagem que possa fazer 
com que seja alcançado a compreensão do procedimento." (E questionário final)

[20]: "Melhoramos o nosso desempenho para o entendimento do texto técnico, busco procurar o melhor sentido para o contexto." $(R$ - questionário final)

Essa preocupação com o contexto de produção e de recepção dos textos mostra que os alunos ampliaram suas visões sobre tradução durante o curso, as quais, no início, baseavam-se principalmente em aspectos estruturais da língua. Essa mudança de visão sobre tradução, revela que os alunos não acreditam mais no "intercâmbio com perfeito equilíbrio entre as línguas" (RODRIGUES, 2000, p. 225) e que são capazes de refletir sobre as diferenças que são inerentes a qualquer situação de tradução, ponto de vista ilustrado no excerto abaixo:

[21] "Essas atividades mostraram que há palavras que não possuem um significado em português para o contexto, entre outros.” $(R-$ questionário final)

[22] "Porque ajuda a conhecer mais palavras em inglês e a entender que alguns termos não têm tradução." (C - questionário final)

A partir desses comentários, consideramos que as 25 (vinte e cinco) horas de aula haviam sido suficientes para promover uma reflexão sobre o papel da tradução no ensino instrumental de línguas e contemplar os tópicos necessários para a reformulação de algumas crenças sobre tradução, que poderiam atrapalhar o rendimento dos alunos durante as aulas de Inglês Instrumental. Todos os alunos que responderam ao questionário final concordaram com a afirmação de que as atividades de tradução desenvolvidas pela professora/pesquisadora contribuíram para o cumprimento dos objetivos do curso de Informática para Internet.

\section{Considerações finais}

O questionário sobre crenças, o conhecimento prévio da professora/pesquisadora sobre tradução na área técnica e o trabalho colaborativo ajudou-nos a: 1) verificar o que os alunos já conheciam 
sobre tradução; 2) observar suas crenças em relação ao processo tradutório e suas funções em um curso de Inglês Instrumental; 3) selecionar e elaborar material adequado para o cumprimento dos objetivos do curso. Os exercícios de tradução realizados durante o curso favoreceram a identificação das possíveis dificuldades mencionadas anteriormente pelos alunos em seus questionários e apontaram outras questões que eles não haviam pensado antes, como o a importância de se atentar à tipologia textual, ao contexto de produção e de recepção dos textos e à relação entre língua e ideologia.

Percebemos que, ao estarem em contato com a tradução especializada, os alunos ampliaram suas percepções sobre as características desses tipos de texto e souberam tirar proveito das atividades de tradução para melhorarem as suas habilidades de leitura de textos especializados, e seus conhecimentos sobre a estrutura e funcionamento da língua inglesa e da língua portuguesa.

Além dos alunos, a professora/pesquisadora também passou por transformações durante essa pesquisa. Conforme mostramos, o levantamento das crenças dos alunos e a observação de suas práticas em sala de aula levaram a uma reformulação constante do material e das práticas pedagógicas da professora/pesquisadora.

Os resultados dessa pesquisa corroboram a idéia de que as teorias podem ser produzidas por meio de práticas e de que as práticas sempre refletem alguma teoria. Em adição, acreditamos que o levantamento das crenças e o diálogo colaborativo empreendido pela professora/pesquisadora em sala de aula auxiliou na reconstrução das crenças sobre tradução e na reflexão sobre a relação entre tradução e ensino instrumental de línguas.

\section{Referências}

ALMEIDA FILHO, José C. P. Dimensões comunicativas no ensino de línguas. 2. ed. Campinas: Pontes, 1998.

ARANHA, Solange. Contribuições linguísticas para a argumentação da introdução acadêmica. 2004. 172 f. Tese (Doutorado) Universidade Estadual Paulista, Faculdade de Ciências e Letras. Araraquara, 2004. 
BARCELOS, Ana M. F.; BATISTA, Fernanda S.; ANDRADE, Juliana C. Ser professor de inglês: crenças, expectativas e dificuldades dos alunos de Letras. In: VIEIRA-ABRAHÃO, Maria H. Prática de ensino de língua estrangeira: experiências e reflexões. Campinas: Pontes, 2004.

BARCELOS, Ana M. F., VIEIRA-ABRAHÃO, Maria H. Crenças $e$ ensino de línguas: foco no professor, no aluno e na formação de professores. Campinas, SP: Pontes, 2006.

BARROS, Lídia A. Curso básico de terminologia. São Paulo: USP, 2004.

BORG, Simon. Teacher cognition and language education. New York: Continuum, 2006.

CAMARGO, Diva C. Tradução e tipologia textual. In: Tradução $e$ comunicação. São Paulo, v.16, p.46-52, 2007.

COCHRAN-SMITH, M.; LYTLE, S. Inside-outside: teacher research and knowledge. New York: Teachers College Press, 1993.

HAWKINS, Margaret; NORTON, Bonny. Critical language teacher education. In: BURNS, Anne; RICHARDS, Jack C. (Orgs.). The Cambridge guide to second language teacher education. Cambridge: Cambridge University Press, 2009.

HOLMES, John; CELANI, Maria A. A. Sustainability and local knowledge: the case of the Brazilian ESP project 1980-2005. English for Specific Purposes, v.25, 109-122, 2006.

JAKOBSON, Roman. Linguística e comunicação. Tradução de Isidoro Blikstein e José Paulo Paes. São Paulo: Cultrix, 1970.

LIBERALI, Fernanda C. Formação crítica de educadores: questões fundamentais. Taubaté-SP: Cabral Editora e Livraria Universitária, 2008. 
MALMKJAER, Kirsten. Translation \& language teaching. Manchaster: St. Jerome, 1998.

PAGANO, Adriana. Crenças sobre a tradução e o tradutor. In: PAGANO, Adriana; MAGALHÃES, Célia; ALVES, Fabio. Traduzir com autonomia: estratégias para o tradutor em formação. São Paulo: Contexto, 2009.

ROBINSON, Pauline. ESP: English for Specific Purposes. Pergamon Press, 1980.

RODRIGUES, Cristina C. Tradução e diferença. São Paulo: Editora UNESP, 2000.

VYGOTSKY, Lev S. A construção do pensamento e da linguagem. Tradução: Paulo Bezerra. São Paulo: Martins Fontes, 2000.

ZEICHNER, Kenneth. Uma análise crítica sobre a "reflexão" como conceito estruturante na formação docente. Educação \& Sociedade, v. 29, p. 535-554, 2008.

Recebido em: 15/01/2011

Aceito em: $\quad$ 17/09/2011

Title: Beliefs of students enrolled in a technical course about the role of translation in ESP teaching 